04;15

\title{
Действие продуктов плазмы поверхностного барьерного разряда на прорастание злаков
}

\author{
() А.В. Лазукин ${ }^{1,2}$, О.И. Грабельных ${ }^{3,4}$, Ю.А. Сердюков ${ }^{1,2}$, Т.П. Побежимова ${ }^{3}$, В.Н. Нурминскийㄱ, \\ А.В. Корсукова ${ }^{3,4}$, С.А. Кривов ${ }^{1}$ \\ ${ }^{1}$ Национальный исследовательский университет „МЭИ“, Москва, Россия \\ ${ }^{2}$ Институт физиологии растений им. К.А. Тимирязева РАН, Москва, Россия \\ ${ }^{3}$ Сибирский институт физиологии и биохимии растений СО РАН, Иркутск, Россия \\ ${ }^{4}$ Иркутский государственный университет, Иркутск, Россия \\ E-mail: lazukin_av@mail.ru
}

Поступило в Редакцию 17 сентября 2018 г.

Рассмотрена обработка семян зерновых культур (яровая пшеница, озимая пшеница, озимое тритикале и озимая рожь) продуктами плазмы поверхностного диэлектрического барьерного разряда при изменении времени экспозиции (30 и $60 \mathrm{~min})$ в условиях расположения семян вне зоны активного действия разряда. Показано, что семена злаков неодинаково отвечают на обработку, что связано, вероятно, со степенью устойчивости к окислительному стрессу. Ответ на обработку при расположении семян вне зоны активного действия разряда проявляется при более значительных временах, чем в случае прямой обработки семян продуктами поверхностного разряда.

DOI: 10.21883/PJTF.2019.02.47216.17529

В последние годы показана эффективность применения низкотемпературной плазмы в агротехнологии [1]. В частности, речь идет о воздействии на семена культурных растений продуктами плазмы объемного и поверхностного барьерного разряда (ПБР). Для ПБР показана эффективность при воздействии на семена злаков различных сортов [2-5]. Предполагается, что действие разряда изменяет водный статус экспонированных семян, их смачиваемость и структуру поверхности (образование микроповреждений, микропор), а также значительно снижает фитопатогенную нагрузку на прорастающее семя. При этом семена могут обрабатываться по двум схемам: они могут быть помещены в разряд (в случае ПБР семена расположены на поверхности диэлектрического барьера у коронирующих электродов) [2-4] либо отделены от диэлектрического барьера небольшим промежутком $[5,6]$. В каждом из вариантов обработки имеются свои особенности воздействия на семя. Так, в первом варианте семя экспонируется в сильном электрическом поле, интенсивном излучении разряда, ионном ветре, под действием повышенной температуры барьера, значительной концентрации химически активных соединений. На поверхности семени формируются точки привязки отдельных микроразрядов, к нему переносится в кратковременных импульсах электрический заряд. Во втором варианте (локальное удаление на расстояние 5-10 mm) количество действующих факторов сокращается. К ним относится воздействие относительно долго живущих химических соединений (озон, оксиды азота и т.д.), напряженности переменного электрического поля и ионного ветра. В каждой из описанных схем можно обеспечить эффективный ответ на обработку семян злаков. Оптимальное время обработки составляет единицы минут. При этом необходимо учитывать, что именно ионный ветер может играть ведущую роль в обработке, так как обеспечивает перенос химических агентов и заряженных частиц, способствует удалению влаги. Удаление влаги с поверхности (и как следствие изменение водного баланса в семени) может быть доминирующим фактором в управлении последующим прорастанием. С другой стороны, долгоживущие активные химические соединения и аэроионы играют важную роль в борьбе с фитопатогенной нагрузкой и в оздоровлении семени. Прояснить роль прямого действия ионного ветра, создаваемого системой ПБР, можно за счет удаления посевного материала в области по краям от коронирующих электродов.

Целью данного исследования является прояснение роли долгоживущих химических соединений, создаваемых ПБР, в процессе модулирования прорастания семян злаков. Сокращение числа действующих на семена факторов достигается за счет расположения семян относительно электродной системы ПБР.

Электродная система ПБР состояла из двух полосовых электродов шириной $1 \mathrm{~mm}$ (к полосам приложено синусоидальное напряжение с действующим значением $2.4 \mathrm{kV}$ и частотой $30 \mathrm{kHz}$ ), находящихся на расстоянии $30 \mathrm{~mm}$ друг от друга на барьере из корундовой керамики толщиной $1 \mathrm{~mm}$, и заземленного обратного электрода. Электродная система помещалась в контейнер объемом 0.71 вместе с обрабатываемой пробой семян (60-80g). Схема расположения посевного материала и электродов в контейнере показана на рис. 1. Электродная система приподнята на радиаторе относительно дна контейнера. Проба семян располагается по дну контейнера в один слой. Обработка проводится во влажном атмосферном воздухе без циркуляции. Время экспозиции составляет 30 и $60 \mathrm{~min}$. 


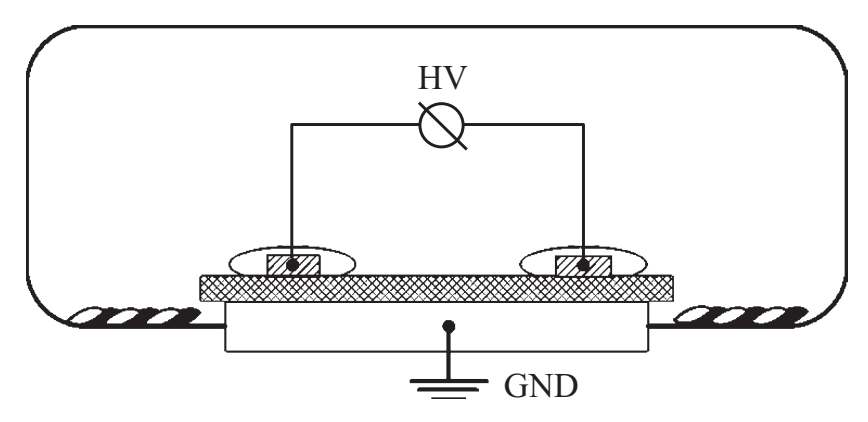

Рис. 1. Разрядная камера для обработки посевного материала.

В работе использовались семена мягкой озимой пшеницы (сорт „Иркутская““, урожай 2017 г.), мягкой яровой пшеницы (сорт „Новосибирская-29“, урожай 2015 г.), озимого тритикале (сортообразец 430-6002, урожай 2016 г.), озимой ржи (сорт „Чулпан“, урожай 2014г.). Семена проращивались трое или шесть суток в четырех повторах по 50 семян на вариант на одном слое фильтровальной бумаги, увлажненной дистиллированной водой, в темноте в термостате при $24^{\circ} \mathrm{C}$. В конце опыта определялись количество проросших семян, длина побега индивидуальных проростков, длина каждого корня. На гистограммах (рис. 2 и 3 ) приведены средние значения с указанием $95 \%$ доверительных интервалов. Достоверность отличий между вариантами подтверждалась с помощью теста множественных сравнений Тьюки. Варианты, не имеющие достоверных отличий, обозначены одинаковыми литерами. Статистическая обработка данных проведена с помощью языка программирования R.

Семена злаков, выбранных для исследования, имели различную всхожесть. Как оказалось, различия всхожести не влияли на ответную реакцию семян злаков на воздействие продуктов плазмы ПБР (рис. $2, a$ ). Даже при обработке в течение $30 \mathrm{~min}$ не наблюдалось достоверного ответа всхожести и морфометрических показателей проростков злаков, кроме озимой пшеницы, у которой обработка семян вызывала удлинение побега (рис. 2,b) и корней (рис. 2, c) проростков. При увеличении длительности экспозиции семян до $60 \mathrm{~min}$ у проростков озимой пшеницы происходило достоверное увеличение суммарной длины корней (при $30 \mathrm{~min}$ экспозиции наблюдается тенденция к увеличению корневой системы, при $60 \mathrm{~min}$ - достоверное увеличение) (рис. $3, b$ ). На шестые сутки роста проростков тенденция к увеличению длины корневой системы сохранялась (рис. $3, b$ ). Стимуляция роста побега во всех рассмотренных вариантах обнаруживалась только у трехсуточных проростков озимой пшеницы (рис. $2, b, 3, a)$.

Семена озимой пшеницы проявили наибольшую отзывчивость к обработке, в то время как семена других культур (независимо от их всхожести) не реагировали на воздействие. Известно, что одним из основных долгоживущих продуктов плазмы ПБР является озон. Озон сильный окислитель, провоцирует образование активных форм кислорода и развитие окислительного стресса, в зависимости от его концентрации и длительности воздействия, стадии онтогенеза растений и уровня их антиоксидантной защиты оказывает разнонаправленный эффект на физиолого-биохимические процессы, протекающие в клетках растений [7]. Озонирование считается
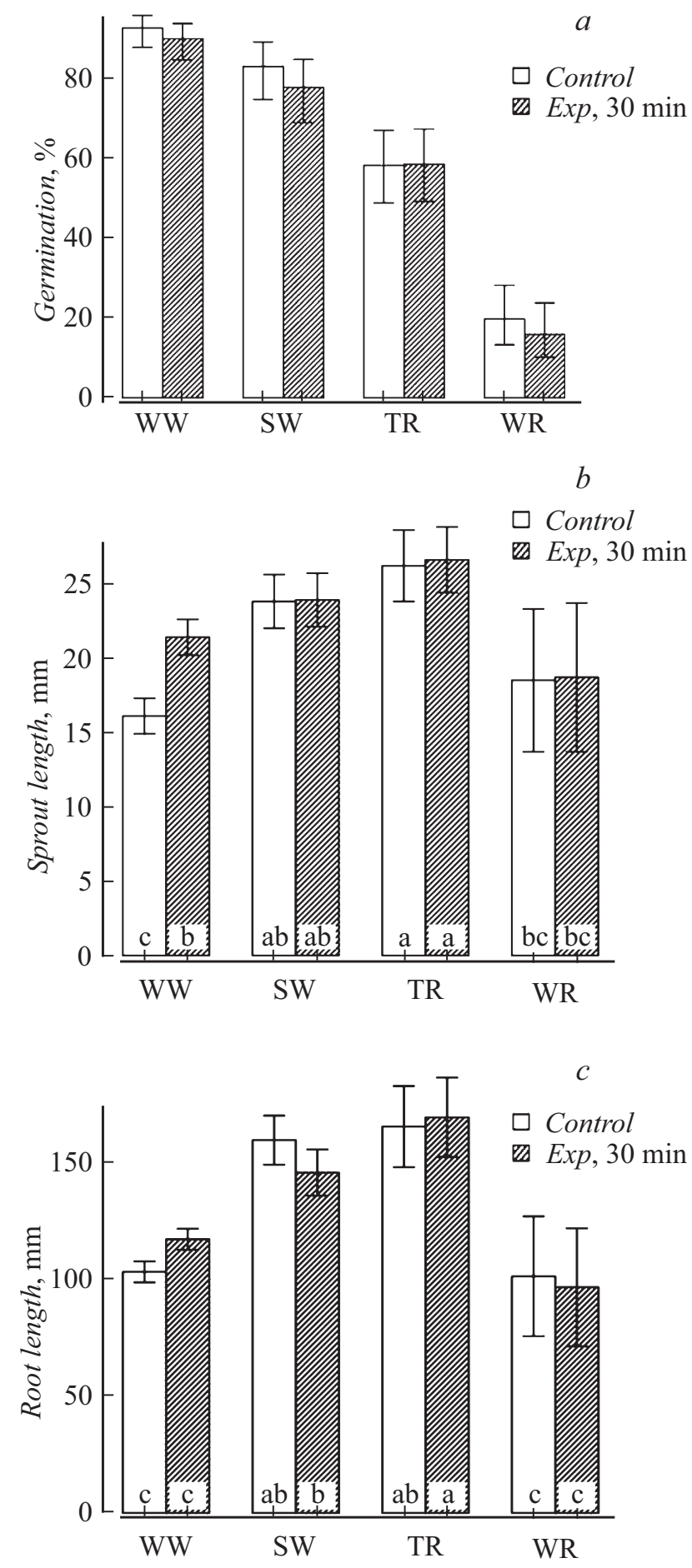

Рис. 2. Влияние обработки семян (30 min) на всхожесть $(a)$, длину побегов $(b)$ и общую длину корней $(c)$ трехсуточных проростков озимой пшеницы (WW), яровой пшеницы $(\mathrm{SW})$, озимого тритикале (TR), озимой ржи (WR). 

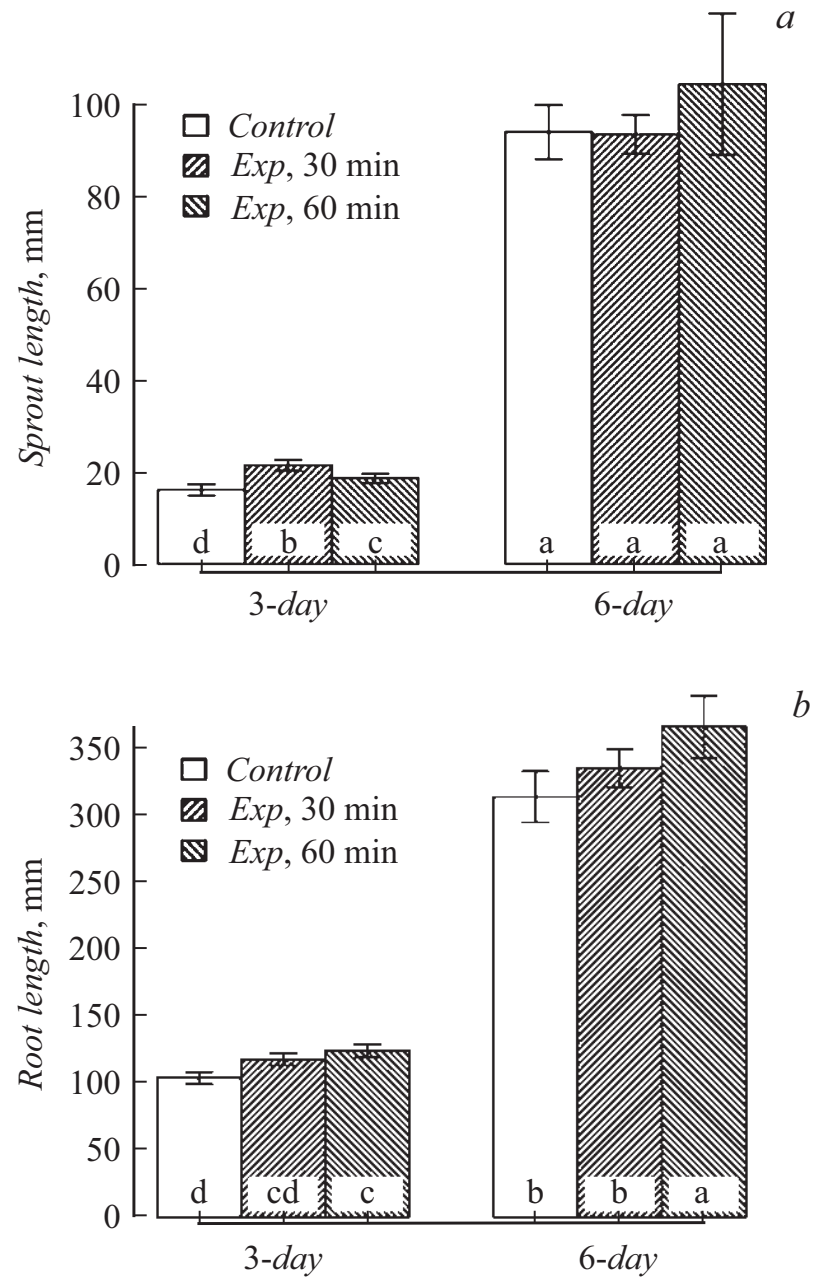

Рис. 3. Длина побегов $(a)$ и общая длина корней $(b)$ проростков озимой пшеницы (трех- и шестисуточных), выращенных из семян, обработанных плазмой поверхностного барьерного разряда (30 и $60 \mathrm{~min})$.

одним из методов, снижающих микобиотическое загрязнение посевного материала и зернового сырья, используемого в питании [8]. Установлено, что фунгицидный эффект озона зависит от его концентрации, длительности экспозиции, массы семян и влажности зерна. Обработка озоном способна ингибировать рост на поверхности зерна пшеницы грибов рода Fusarium [8-12], Geotrichum, Myrothecium и Mucor [9]. Обработка озоном не только ингибировала рост грибов, но и эффективно снижала содержание микотоксинов Fusarium [11-13] и общий уровень афлатоксина [12]. Скорость деградации отдельных микотоксинов зависит от длительности озонирования [13]. В проведенных исследованиях физических и биохимических изменений в зерне пшеницы не отмечалось [11]. Также выявлено [14], что от содержания антиоксидантов зависит реакция зерна на обработку озоном.

Возможными объяснениями различий в реакции семян изученных в настоящей работе злаков на обработку являются как разная эффективность функционирования их антиоксидантной системы, связанная, в частности, со сроком хранения семян, так и различная фитопатогенная нагрузка на прорастающее семя.

При сокращении числа действующих факторов время эффективного воздействия оказывается значительным (выше $30 \mathrm{~min}$ ). Также при подобной обработке продуктами ПБР не удается повысить всхожесть семян даже в случае крайне низкой всхожести. Это указывает на то, что изолированное действие долгоживущих химических агентов не является основным путем воздействия на прорастание. Тем не менее выявленное в работе стимулирование роста корней (отмечается на третьи сутки роста и сохраняется на шестые сутки) у проростков озимой пшеницы позволит в дальнейшем увеличить продуктивность и урожайность растений.

Остается открытым вопрос о роли степени зараженности семян при формировании положительного (эффективного) ответа на обработку. Для прояснения этого обстоятельства предполагается провести исследование на предварительно обеззараженных с применением протравителей семенах.

Работа выполнена с использованием коллекций ЦКП „Биоресурсный центр“ и ЦКП „Биоаналитика“ Сибирского института физиологии и биохимии растений $\mathrm{CO}$ РАН (Иркутск).

Исследование проведено за счет гранта Российского научного фонда (проект № 18-76-10019).

\section{Список литературы}

[1] Šerá B., Šerý M. // Plasma Sci. Technol. 2018. V. 20. N 4. P. 044012 (1-8). https://doi.org/10.1088/2058-6272/aaacc6

[2] Dobrin D., Magureanu M., Mandache N., Ionita M.D. // Innov. Food Sci. Emerg. Technol. 2015. V. 29. P. 255-260. DOI: 10.1016/j.ifset.2015.02.006

[3] Zahoranová A., Henselová M., Hudecová D., Kaliňáková B., Kováčik D., Medvecká V., Černák M. // Plasma Chem. Plasma Process. 2016. V. 36. N 2. P. 397-414.

DOI: $10.1007 / \mathrm{s} 11090-015-9684-\mathrm{z}$

[4] Park Y., Oh K.S., Oh J., Seok D.C., Kim S.B., Yoo S.J., Lee M.J. // Plasma Process Polym. 2018. V. 15. N 2. P. 1600056. DOI: 10.1002/ppap.201600056

[5] Lazukin A., Krivov S., Nikitin A., Lyubushkina I., Grabelnych O., Michalevskii V., Novodvorskii O. // High Temp. Mater. Process. 2014. V. 18. N 1-2. P. 131-134. DOI: 10.1615/HighTempMatProc.2015015563

[6] Lazukin A.V., Serdukov Y.A., Pinchuk M.E., Stepanova O.M., Krivov S.A., Grabelnykh O.I. // J. Phys.: Conf. Ser. 2018. V. 946. N 1. P. 012140. DOI: $10.1088 / 1742-6596 / 946 / 1 / 012140$

[7] Ozone pollution: a hidden threat to food security. Report prepared by the ICP Vegetation / Eds G. Mills, H. Harmens. Wales (UK): ICP Vegetation Programme Coordination Centre, Centre for Ecology and Hydrology, 2011. 112 p.

[8] Steponavičius D., Raila A., Steponavičiené A., Lugauskas A., Kemzūraité A. // Ann. Agric. Environ. Med. 2012. V. 19. N 2. P. 193-201. 
[9] Raila A., Lugauskas A., Steponavičius D., Railiené M., Steponavičiené A., Zvicevičius E. // Ann. Agric. Environ. Med. 2006. V. 13. N 2. P. 287-294.

[10] Marique T., Allard O., Spanoghe M. // Int. J. Microbiol. 2012. V. 2012. P. 865175 (1-5). DOI: 10.1155/2012/865175

[11] Savi G.D., Piacentini K.C., Bittencourt K.O., Scussel V.M. // J. Stored Prod. Res. 2014. V. 59. P. 245-253.

DOI: $10.1016 /$ j.jspr.2014.03.008

[12] Trombete F.M., Porto Y.D., Freitas-Silva O., Pereira R.V., Direito G.M., Saldanha T., Fraga M.E. // J. Food Process. Pres. 2016. V. 41. N 3. P. e12927. DOI: 10.1111/jfpp.12927

[13] Reinholds I., Juodeikiene G., Bartkiene E., Zadeike D., Bartkevics V., Krungleviciute V., Cernauskas D., Cižeikiene D. // World Mycotoxin J. 2016. V. 9. N 3. P. 409-417. DOI: 10.3920/WMJ2015.2011

[14] Eabanowska M., Kurdziel M., Filek M. // J. Plant Physiol. 2016. V. 190. P. 54-66. DOI: 10.1016/j.jplph.2015.10.011 